\title{
Pre- and post-trial stimulation: Effects on retention'
}

WILLIAM H. CALHOUN AND ROBERT J. MURPHY

UNIVERSITY OF TENNESSEE

Mice were shocked for stepping from a small platform; retention was tested $24 \mathrm{hr}$. later. Stimulation level was controlled during the immediate pre- or post-learning period. Mice stimulated for $30 \mathrm{~min}$. following learning retained the the same as nontreated $S s$, while mice placed into a dark, quiet environment retained more. Ss stimulated pre-learning were slightly superior to nontreated animals.

According to consolidation theory memory formation is dual trace: initially a fragile trace and later a relatively permanent one. Long-term traces require a brief period (consolidation time) to develop from initial traces. Retroactive inhibition occurs when shortterm traces are disrupted so consolidation is blocked. Substantial support has come from studies with electroconclusive shock (ECS) (Glickman, 1961). Yet, in many situations forgetting occurs, even though no extraordinary event such as ECS is present. Therefore, it cannot be established by studies with ECS alone that consolidation theory is appropriate for explaining "usual" forgetting. An alternative approach would be to focus on events in the usual post-learning environment which must be responsible for interfering with consolidation (if consolidation theory is correct). Following this approach, Minami \& Dallenbach (1946) studied retention of a shock avoidance response in cockroaches. Ss immobilized in dark after learning retained more than if allowed normal activity in light. Thompson \& Bryant (1955) and Thompson (1957) tested rats and found superior performance with Ss placed in the dark following training and faster relearning when Ss spent $48 \mathrm{hr}$. in dark following training.

These results provide support for consolidation theory relevant to everyday forgetting. However, conditions were markedly different, and species dissimilar. This investigator designed a study with mice (Calhoun, 1966); Ss were given $10 \mathrm{trials} /$ day for five days on a spatial discrimination. For $20 \mathrm{~min}$. after each day's training Ss were subjected to either no-stimulation (Sin a sounddeadened box) or stimulation (a bright flashing light, pulsing buzzer, and a platform that rocked). Contrary to previous work, the no-stimulation group did not learn faster.

In view of Thompson's positive results, a definitive conclusion could not be drawn. Therefore, the experiments to be reported were planned. A one-trial step-off problem was selected as learning is accomplished within a very short period (Essman \& Alpern, 1964). A further advantage is that post-learning treatments have been shown to disrupt retention (ether anesthesia, Abt et al, 1961; ECS, Madsen \& McGaugh, 1961).

\section{Experiment I}

Ss were male mice of a random bred strain (Ha/IRC). The learning task was one in which $S$ was placed on a raised small circular platform ( 3 in. in diameter) in the center of a large rectangular one (11 in. $x 15$ in.). It was lowered until the platform reached full down $(1 / 2$ in. from base). S invariably stepped from the small platform, completed a circuit between the two platforms, and received a foot-shock. Step-off latency was recorded. Twenty-four $h r$. later $S$ was once again placed on the raised platform and it then lowered. If the animal had learned, it would hesitate to step off again, as indicated by an increased latency.

Stimulation was controlled either during the immediate $30-\mathrm{min}$. pre- or post-learning period. For stimulation treatment $S$ was placed into the box which contained three 45-watt light bulbs, a buzzer, and a platform that moved back-and-forth. For no-stimulation $\mathrm{S}$ was placed into a dark, sound-deadened box.

Treatment groups were: PO-S (post-stimulation), stimulation after the trial; PR-S (pre-stimulation), stimulation immediately preceding the trial; PO-NS (post-no-stimulation), dark box after trial; and NT (nontreated).

One hundred eleven Ss were tested in blocks of 36,35 , and 40 . Two 250 microfarad capacitors, charged by a dc power source, discharged when the forefeet of $\mathrm{S}$ touched the lower platform. The results, in terms of median increase in latency on retest $(\Delta T)$, are presented in Table 1 . The $\Delta T^{\prime}$ 's differed over blocks, but the general nature of the treatment effect was highly similar within blocks. An analysis of variance, the median as a single measure, was conducted. Treatments $(F=8.58$, $\mathrm{df}=3 / 6)$ and the Blocks $(F=8.94, \mathrm{df}=2 / 6)$ were significant $(p<.05)$. By Dunnett's test the PR-S and PO-NS groups were significantly superior to the nontreated group $(p<.01)$.

The two major findings were: (1) Protection from stimulation during the immediate post-learning period (PO-NS condition) allowed for greater retention than if the animal was returned to the normal environment.

Table 1. Median $\Delta T^{\prime}$ 's in seconds. Number of animals tested is in parentheses.

\begin{tabular}{lccccc} 
Block & Age & \multicolumn{4}{c}{ Stimulation Condition } \\
\cline { 3 - 6 } & & PO-S & PR-S & PO-NS & NT \\
\hline 1 & 65 & $3.0(9)$ & $9.0(9)$ & $6.0(9)$ & $3.0(9)$ \\
2 & 110 & $5.5(9)$ & $11.0(9)$ & $10.0(9)$ & $6.8(8)$ \\
3 & 70 & $1.2(10)$ & $4.0(10)$ & $8.2(10)$ & $1.5(10)$ \\
$\bar{\chi}$ & & 3.2 & 8.0 & 8.1 & 3.8 \\
\hline
\end{tabular}


This would be predicted from consolidation theory, and agrees with most earlier work discussed above. (2) Treatment with stimulation in the pre-learning period produced superior retention. This is surprising; such proactive effects are not encompassed by consolidation theory. This effect could be a facilitation of learning, not unlike that reported for drugs such as strychnine (McGaugh \& Petrinovich, 1965). There was no obvious disruption of consolidation by post-learning stimulation; the PO-S group was almost identical to the nontreated group.

\section{Experiment II}

This was essentially a replication of Experiment I, but with some improvements in apparatus. Shock was delivered directly by a constant current dc power supply, and a Hunter interval timer was used to control shock duration. Now when $S$ placed both forefeet on the lower platform, a switch was manually closed so a $0.4 \mathrm{ma}$ shock was delivered for $1 \mathrm{sec}$. Latency was recorded automatically.

Ninety-two male mice were tested in blocks of 28 , 32 , and 32 . The results of this experiment are presented in Table 2. A large increase in $\Delta T^{\prime}$ 's over those in Experiment I was found, indicating effective shock intensity was higher. Again, PO-S and NT conditions produced nearly the same effect. The major effect was found for the PO-NS condition. The overall $\mathrm{F}$ was not significant $(F=2.06, d f=3 / 6)$, but the Dunnett's test did show the PO-NS group to be significantly superior $(p<.01)$ to the nontreated group. ${ }^{2}$

\section{Discussion}

The major result, consistent for the two experiments, was effect of reduced stimulation during the immediate post-learning period. Facilitation by pre-stimulation found in the Experiment I did not appear to replicate. However, note that the difference in $\Delta T^{\prime} s$ between the NT and PR-S conditions in both experiments was about

Table 2. Median $\Delta T^{\prime}$ 's in seconds. Number of animals tested is in parentheses.

\begin{tabular}{lllllr} 
Block & Age & \multicolumn{4}{c}{ Stimulation Condition } \\
\cline { 3 - 6 } & & PO-S & PR-S & PO-NS & \multicolumn{1}{c}{ NT } \\
\hline 1 & 95 & $20.6(7)$ & $31.5(7)$ & $142.5(7)$ & $32.1(7)$ \\
2 & 70 & $15.2(8)$ & $17.5(8)$ & $33.9(8)$ & $9.7(8)$ \\
3 & 77 & $14.3(8)$ & $11.2(8)$ & $21.8(8)$ & $8.8(8)$ \\
$\bar{X}$ & & 16.7 & 20.1 & 66.1 & 16.9 \\
\hline
\end{tabular}

the same (4.2 and 3.2 respectively). This may indicate a small, consistent effect.

Post-learning treatment with stimulation did not have a disruptive effect when this condition was compared with animals returned directly to the colony room. This could indicate that the stimulation was not disruptive. In order to make a strong case for consolidation theory, disruptive effects of high stimulation must be shown. However, it is possible that stimulation intensity tested was not sufficiently high to have a greater disruptive effect than the stimulation present in the usual postlearning environment. There is no doubt that the condition of post-learning stimulation as well as the colony room stimulation conditions (NT) were associated with inferior performance in comparison with the postlearning no-stimulation treatment. This is in agreement with consolidation theory; presumably the animals protected from stimulation for the $30-\mathrm{min}$. period following learning were able to more fully consolidate the experience. Yet, this does not preclude alternative explanations.

\section{References}

Abt, J. P., Essman, W. B., \& Jarvik, M. F. Ether-induced retrograde amnesia for one-trial conditioning in mice. Science, 1961, 133, 1477-1478.

Calhoun, W. H. The effect of level of external stimulation on learning and the interaction of this effect with strychnine treatment in mice. Psychol. Rep., 1966, 18, 715-722.

Essman, W. B., \& Alpern, H. Single trial conditioning: Methodology and results with mice. Psychol. Rep., 1964, 14, 731-740.

Glickman, S. E. Perseverative neural processes and consolidation of the neural trace. Psychol. Bull., 1961, 58, 218-233.

Madsen, M. C., \& McGaugh, J. L. The effect of ECS on one-trial avoidance learning. J. comp. physiol. Psychol., 1961, 54, 522523 .

McGaugh, J. L., \& Petrinovich, L. Effects of drugs on learning and memory, Int. rev. of Neurobiol., 1965, 8, 139-196.

Minami, H., \& Dallenbach, K. M. The effect of activity upon learnand retention in the cockroach. Amer. J. Psychol., 1946, 59, 1-58

Thompson, R. Retroactive effect of interpolated visual stimulation. Psychol. Rep., 1957, 3, 183-188.

Thompson, R., \& Bryant, J. H. Memory as affected by activity of the relevant receptor. Psychol. Re $p, 1955,1,393-400$.

\section{Notes}

1. These results were presented at the Southeastern Psychological Association 1966 meeting in New Orleans. Supported by NIMH grant No. MH 11722-01.

2. Dunnett's test is appropriate even though the overall F was not significant. See Winer, B. J., Statistical principles in experimental design, McGraw-Hill, 1962, pp. 89-92. 